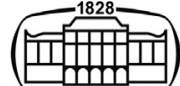

AKADÉMIAI KIADÓ

\section{Acta Veterinaria}

Hungarica

$68(2020) 1,49-52$

DOI:

$10.1556 / 004.2020 .00012$

(c) 2020 Akadémiai Kiadó, Budapest

\title{
Intestinal ganglioneuroma in a neonatal Japanese black calf - Short communication
}

\section{JUN SASAKI ${ }^{*}$, YUSUKE KURODA ${ }^{1}$, ATSUSHI UEKI ${ }^{2}$, BHUMINAND DEVKOTA ${ }^{1,3}$ and NORIO YAMAGISHI ${ }^{1,4}$}

\author{
${ }^{1}$ Department of Veterinary Pathology, Faculty of Agriculture, Iwate University, 3-18-8 Ueda, \\ Morioka, Iwate, 020-8550, Japan \\ ${ }^{2}$ Ueki Veterinary Hospital, Morioka, Iwate, Japan \\ ${ }^{3}$ Center for Biotechnology, Agriculture and Forestry University, Rampur, Chitwan, Nepal \\ ${ }^{4}$ Department of Veterinary Sciences, Obihiro University of Agriculture and Veterinary Medicine, \\ Obihiro, Hokkaido, Japan
}

Received: July 13, 2019 • Accepted: November 19, 2019

Published online: May 8, 2020

\section{ORIGINAL ARTICLE}

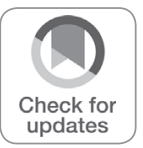

*Corresponding author. Phone: +81 196216166.

E-mail: sasajun@iwate-u.ac.jp

\begin{abstract}
A 1-day-old male calf presented with clinical signs of severe progressive abdominal distension. Abdominal radiographic and ultrasonic images revealed several loop-like structures in the small intestine, which were indicative of gas retention. Experimental laparotomy was performed. However, the calf died during surgery. At necropsy, a round, well-circumscribed mass $(3 \times 3 \times 2.5 \mathrm{~cm})$ was found in the jejunal wall, and the jejunal lumen was narrowed. The mass was firm and had white to grey appearance on the cut surface. Histologically, the submucosa and the muscle layer were diffusely thickened due to abundance of neural tissues comprising several fascicles of nerve fibres and large aggregates of ganglion cells. Some ganglion cells contained basophilic Nissl substances in their cytoplasm. Immunohistochemically, these cells were positive for S-100 and synaptophysin. Ultrastructural examination revealed that the neoplastic ganglion cells contained dense core vesicles in the cytoplasm. Based on these findings, the neoplastic lesion was diagnosed as ganglioneuroma in the jejunum.
\end{abstract}

\section{KEYWORDS}

calf, congenital, ganglioneuroma, intestine, Japanese black

Ganglioneuroma is a rare tumour of the peripheral nervous system and is considered a benign neoplasm comprising both mature ganglion cells and nerve fascicles with axons, Schwann cells, fibroblasts and connective tissues (Koestner et al., 1999). This type of tumour has been observed in domestic animals, such as cattle (Cimprich and Ardington, 1975; Sokale and Ladds, 1983), horses (Allen et al., 1989; Grossi et al., 2013), pigs (Une et al., 1984; Murakami et al., 2011; Inoue et al., 2016), dogs (van den Ingh and Rothuizen, 1984; Hawkins and Summers, 1987; Ribas et al., 1990; Schueler et al., 1993; Reimer et al., 1999; Hermeyer et al., 2007; Sakai et al., 2011; Goto et al., 2018), cats (Patnaik et al., 1978; Kobayashi et al., 2012), buffaloes (Gupta and Singh, 1978) and cockatiels (Murphy and Shivaprasad, 2008). Ganglioneuroma in cattle has been observed at sites including the adrenal gland (Grossi et al., 2013), the spinal cord (Cimprich and Ardington, 1975), and intraabdominal serosal surfaces (Sokale and Ladds, 1983). In terms of occurrence, ganglioneuromas can be solitary or multifocal, and they are more likely to be slow growing and minimally invasive (Schueler et al., 1993). Ganglioneuroma in the gastrointestinal tract is extremely rare in humans and domestic animals. To the best of our knowledge, there has been no report of an intestinal ganglioneuroma in cattle. Herein, we describe the clinical, histological, immunohistochemical and ultrastructural findings of intestinal ganglioneuroma in a neonatal male calf.

A male calf presented with abdominal distension at birth, and he was brought to the Veterinary Teaching Hospital of Iwate University (VTH, Morioka, Iwate) a day after birth for emergency treatment of a suspected intestinal obstruction. The calf had been delivered with 
the assistance of farmers at birth; then, he stood and was suckled from the dam, although the farmers were aware of a slight distension of the abdomen. Next morning, the calf was laterally recumbent with marked abdominal distension; then, the referring veterinarian was called to visit. After an infusion therapy, the veterinarian decided to bring the calf to our VTH. The calf weighed $35 \mathrm{~kg}$, and his body condition score was normal. The clinical signs included progressive abdominal distension, astasia, enophthalmos due to dehydration, and dyspnoea with open-mouth breathing. Abdominal radiographic and ultrasonic images revealed several loop-like structures indicative of gas retention in the small intestine (Fig. 1A). The significant laboratory findings were leukopenia (white blood cell count of $2,000 \mu \mathrm{L}^{-1}$ ) and mild hypoproteinaemia $(0.054 \mathrm{~g} / \mathrm{L})$. The clinical condition of the calf deteriorated with progressive abdominal distension, despite the infusion therapy. Emergency laparotomy via a right flank incision was performed as intestinal obstruction was suspected. The calf died during surgery. At necropsy, a moderate amount of yellowish ascites with fibrin was observed in the abdominal cavity. Grossly, a round, wellcircumscribed mass $(3 \times 3 \times 2.5 \mathrm{~cm})$ was found in the jejunal wall, and the jejunal lumen was narrowed. The proximal area from the neoplastic mass in the small intestine showed severe dilation due to the presence of gas and a large quantity of watery contents (Fig. 1B and C). The serosal side had normal appearance. The mass was firm and had white to grey appearance on the cut surface. In the proximal small intestine there was a large quantity of watery content which was yellowish in colour, had a rotten smell and filled the abomasum. No other gross findings or metastatic foci were observed in the abdominal organs.
Tissue samples were fixed in $10 \%$ neutral buffered formalin and embedded in paraffin, and $4 \mu \mathrm{m}$ sections were stained with haematoxylin and eosin (HE). In the electron microscope examination, formalin-fixed tissues were postfixed in $3 \%$ glutaraldehyde and $1 \%$ osmium tetroxide and were embedded in Epon 812. Ultrathin sections were stained with uranyl acetate and lead citrate and were examined with an electron microscope (JEM-2100, JEOL Ltd., Tokyo). Immunohistochemistry (IHC) was performed primarily to assess the presence of vimentin (Dako, Glostrup, Denmark; diluted 1:50), S-100 (Dako; diluted 1:1,000), synaptophysin (Dako; diluted 1:200), smooth muscle actin ( $\alpha$-SMA) (Invitrogen, Life Technologies Japan Ltd., Japan; ready-touse) and desmin (Dako; diluted 1:100). Antigen retrieval was performed via heating in $10 \mathrm{~mm}$ sodium citrate acid-buffered solution at $121^{\circ} \mathrm{C}$ for $15 \mathrm{~min}$. IHC was conducted using a biotin-conjugated secondary antibody to link the primary antibody to a streptavidin-peroxidase complex, followed by the application of $3,3^{\prime}$-diaminobenzidine. The procedure was performed according to the manufacturer's instructions $\left(\right.$ LSAB $^{\circledR}+$ System-HRP; DAKO). The sections were counterstained with Mayer's haematoxylin. Bovine intestine was used as positive control.

Histologically, the wall of the jejunal mass was significantly thickened due to the presence of neoplastic tissues. The neoplastic mass was poorly demarcated and comprised ganglion cells interspersed between a disproportionate number of spindle cells and nerve fascicles in the lamina propria and muscle layer (Fig. 2A). The ganglion cells had a large, polygonal cytoplasm and large, single, eccentric, round to oval nuclei with prominent nucleoli. Some ganglion cells contained a small amount of Nissl substance at the periphery
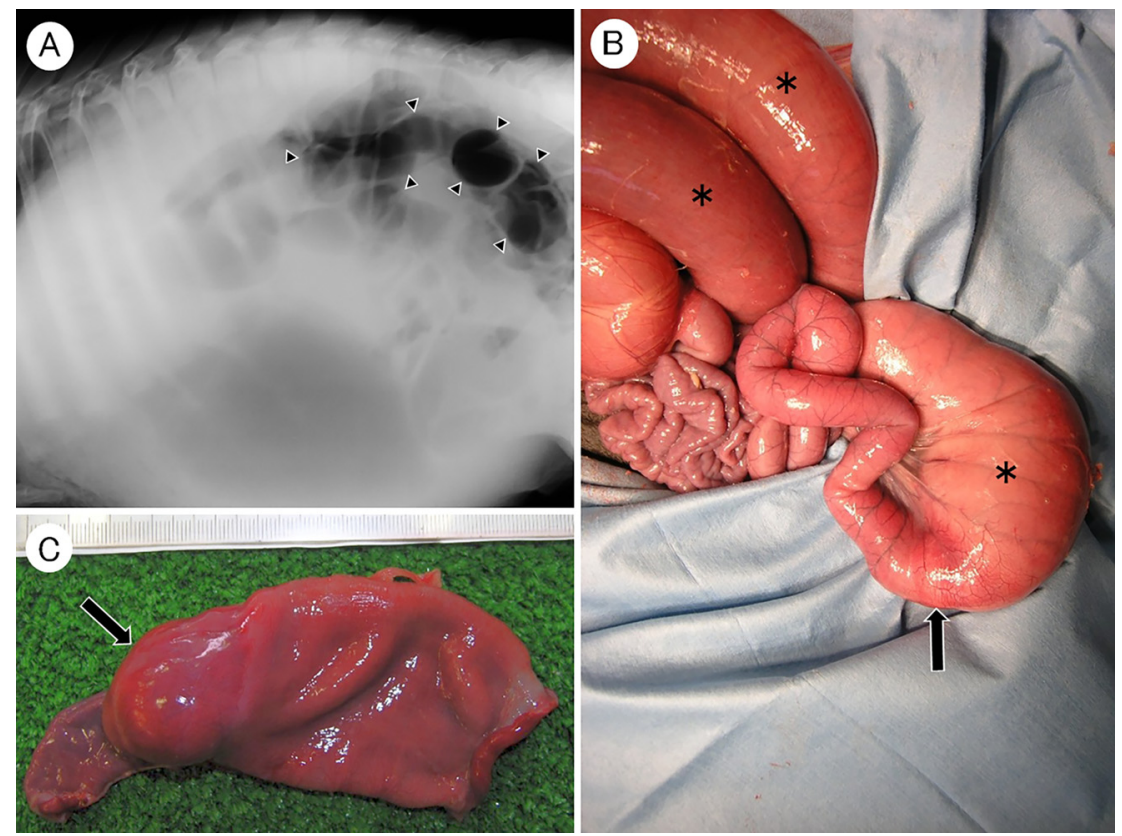

Figure 1. A. Left lateral abdominal radiographic image. The intestine was significantly dilated due to the presence of gas (arrowheads). B. An arrow indicates the location of the neoplastic mass. The area proximal to the neoplastic mass in the small intestine showed severe dilation due to the presence of gas and a large quantity of watery contents (asterisks). C. A round mass was observed in the jejunal wall (arrow) 
of the cytoplasm (Fig. 2B). The diameter of the ganglion cells varied (up to $30 \mu \mathrm{m}$ ), and mitotic figures were not found in the cells. The spindle cells were the predominant cell population and were arranged in bundles. Morphologically, these cells strongly resembled Schwann cells. Cellular atypia, mitotic figures, and metastasis of tumour cells were not observed. In the immunohistochemical examination, the ganglion cells were positive for S-100 and synaptophysin (Fig. 2C and D). The spindle tumour cells resembled Schwann cells and were positive for vimentin and S-100 but negative for desmin and $\alpha$-SMA. Ultrastructurally, the neoplastic ganglion cells had prominent stacks of rough endoplasmic reticulum and a few dense core vesicles (150$200 \mu \mathrm{m}$ in diameter; Fig. 2E). The nerve fascicles comprised fusiform Schwann cells and collagen fibrils with poorly preserved neurofilaments. The Schwann cells showed desmosome-like junctions. Based on these clinical, gross pathological, histological, immunohistochemical and ultrastructural findings, the present case was diagnosed as a ganglioneuroma.

Our investigation revealed that the round mass severely obstructed the jejunal lumen. Therefore, the lesion caused abdominal distension. In this case, the condition was characterised by the proliferation of spindle cells that resembled Schwann cells and ganglion cells in the jejunal wall. Intestinal ganglioneuroma has been observed in domestic animals, such as horse (Allen et al., 1989), pigs (Une et al., 1984; Murakami et al., 2011), and dogs (van den Ingh and Rothuizen, 1984; Ribas et al., 1990; Reimer et al., 1999), but not in cattle. To the best of our knowledge, this is the first reported case of intestinal ganglioneuroma in a calf.

The occurrence of congenital alimentary neoplasms in calves is extremely rare; however, a case of haemangioma of the gingiva at 42 days and a case of lymphoma of the intestine at 2 days were reported (Misdorp, 2002). Thus far, only one case of juvenile intestinal ganglioneuroma in a 6month-old pig has been reported (Murakami et al., 2011). Meanwhile, there is no report about neonatal or juvenile intestinal ganglioneuroma in cattle. Gross pathological and histological findings in a pig resembled those in our case. However, the pig did not present with any clinical signs before it was slaughtered. Based on the clinical signs and the presence of a lesion in the present case, the condition may be a congenital neoplasm.

Ganglioneuroma and other neurogenic intestinal tumours arise from the ganglionated plexuses of the gut. The extensive involvement of the muscular tunics and subserosa in cats indicate that the neoplasm probably originated in the Auerbach's plexus (Patnaik et al., 1978). By contrast, in another study, jejunal ganglioneuroma in a kitten arose from the Meissner's plexus (Kobayashi et al., 2012). Moreover, in a sow, the tumour arose from the submucosal and/or myenteric plexus of the jejunum based on the location and origin of the tumour and the histopathological features (Une et al., 1984; Murakami et al., 2011). In our case, the tumour also originated from the submucosal and/or myenteric plexus of the jejunum. Differential diagnoses included other neuroblastic tumours, such as ganglioneuroblastoma (Riley

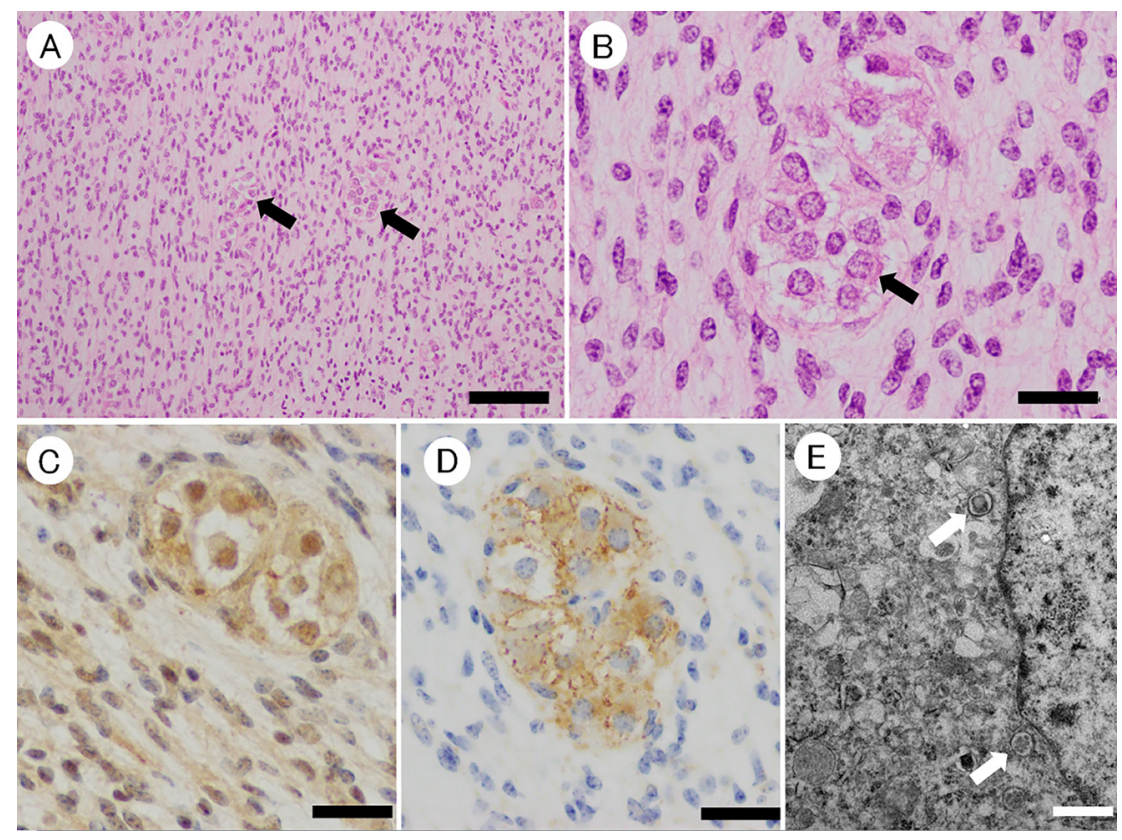

Figure 2. A. The mass comprised of ganglion cells (arrows) interspersed between a disproportionate numbers of spindle cells. Haematoxylin and eosin (HE), Bar $=200 \mu \mathrm{m}$. B. Ganglion cells contained a small amount of Nissl substance at the periphery of the cytoplasm (arrow). HE, Bar $=50 \mu \mathrm{m}$. C. Both spindle and ganglion-like neoplastic cells were immunohistochemically positive for S-100. Immunohistochemistry counterstained with Mayer's haematoxylin, Bar $=50 \mu \mathrm{m}$. D. Ganglion-like neoplastic cells were immunohistochemically positive for synaptophysin. Immunohistochemistry counterstained with Mayer's haematoxylin, Bar $=50 \mu \mathrm{m}$. E. Ganglion cell containing intracytoplasmic dense core vesicles (arrows). Bar $=1 \mu \mathrm{m}$ 
and Forsyth, 1976) and ganglioneuromatosis (Cole et al., 1990). Ganglioneuroblastoma consists of an admixture of ganglioneuromatous and neuroblastomatous components. Ganglioneuromatosis is characterised by diffuse proliferation of nerve fibres and ganglion cells throughout the wall of the intestine and has been associated with multiple endocrine neoplasia. In the present case, a round, well-circumscribed mass was found in the jejunal wall, and neuroblastic components such as rosette patterns were not observed in the lesion.

In conclusion, to the best of our knowledge, this is the first report on congenital ganglioneuroma of the jejunum in a calf.

\section{ACKNOWLEDGEMENT}

The authors thank Mr. Kuniaki Sasaki for his technical assistance with electron microscopy.

\section{REFERENCES}

Allen, D., Swayne, D. and Belknap, J. K. (1989): Ganglioneuroma as a cause of small intestinal obstruction in the horse: A case report. Cornell. Vet. 79, 133-141.

Cimprich, R. and Ardington, P. (1975): Spinal ganglioneuroma in a steer. Vet. Pathol. 12, 59-60.

Cole, D. E., Migaki, G. and Leipold, H. W. (1990): Colonic ganglioneuromatosis in a steer. Vet. Pathol. 27, 461-462.

Goto, M., Yonemaru, K., Hirata, A., Furuhashi, H., Yanai, T. and Sakai, H. (2018): Lingual ganglioneuroma in a dog. J. Vet. Med. Sci. 80, 488-491.

Grossi, A. B., Leifsson, P. S., Jensen, H. E., Vainer, B. and Iburg, T. (2013): Histologic and immunohistochemical classification of 41 bovine adrenal gland neoplasms. Vet. Pathol. 50, 534-542.

Gupta, P. P. and Singh, B. (1978): Ocular ganglioneuroma in Indian water buffaloes (Bubalus bubalis). Vet. Pathol. 15, 138-139.

Hawkins, K. L. and Summers, B. A. (1987): Mediastinal ganglioneuroma in a puppy. Vet. Pathol. 24, 283-285.

Hermeyer, K., Kühn, M., Kuchelmeister, K., Laik, C., Baumgärtner, W. and Wohlsein, P. (2007): Multiple cutaneous ganglioneuromas in a dog. Vet. Dermatol. 18, 360-364.
Inoue, R., Joma, I., Otsubo, K., Matsutake, H., Yanai, T. and Sakai, H. (2016): Cardiac ganglioneuroma in a juvenile pig. J. Vet. Med. Sci. 78, 117-119.

Kobayashi, R., Ohsaki, Y., Yasuno, K., Ogihara, K., Kasai, T., Chambers, J. K., Uchida, K., Saegusa, S., Kamiie, J. and Shirota, K. (2012): A malignant and metastasizing feline cardiac ganglioneuroma. J. Vet. Diagn. Invest. 24, 412-417.

Koestner, A., Bilzer, T., Fatzer, R., Schulman, F. Y., Summer, B. A. and Van Winkle, T. J. (1999): Histological Classification of Tumors of the Nervous System of Domestic Animals, 2nd series. Vol. 5. Armed Forces Institute of Pathology, Washington, D. C.

Misdorp, W. (2002): Tumours in calves: comparative aspects. J. Comp. Path. 127, 96-105.

Murakami, M., Sakai, H., Mizutani, K. and Yanai, T. (2011): Ganglioneuroma in the small intestine of a juvenile pig. J. Vet. Med. Sci. 73, 1501-1504.

Murphy, B. G. and Shivaprasad, H. L. (2008): Ganglioneuroma of the brachial plexus in two cockatiels (Nymphicus hollandicus). Vet. Pathol. 45, 690-692.

Patnaik, A. K., Lieberman, P. H. and Johnson, G. F. (1978): Intestinal ganglioneuroma in a kitten - A case report and review of literature. J. Small Anim. Pract. 19, 735-742.

Reimer, M. E., Leib, M. S., Reimer, M. S., Saunders, G. K. and Johnston, S. A. (1999): Rectal ganglioneuroma in a dog. J. Am. Anim. Hosp. Assoc. 35, 107-110.

Ribas, J. L., Kwapien, R. P. and Pope, E. R. (1990): Immunohistochemistry and ultrastructure of intestinal ganglioneuroma in a dog. Vet. Pathol. 27, 376-379.

Riley, M. G. and Forsyth, W. M. (1976): Bilateral adrenal ganglioneuroblastoma in a premature calf. Aust. Vet. J. 52, 234235.

Sakai, H., Yonemaru, K., Takeda, M., Niimi, K., Murakami, M., Hirata, A. and Yanai, T. (2011): Ganglioneuroma in the urinary bladder of a dog. J. Vet. Med. Sci. 73, 801-803.

Schueler, R. O., Roush, J. K. and Oyster, R. A. (1993): Spinal ganglioneuroma in a dog. J. Am. Vet. Med. Assoc. 203, 539-541.

Sokale, E. O. and Ladds, P. W. (1983): Multicentric ganglioneuroma in a steer. Vet. Pathol. 20, 767-770.

Une, Y., Iwama, K., Yoshida, H., Shirota, K., Nomura, Y. and Saito, Y. (1984): Multiple ganglioneuroma derived from intramural plexus of jejunum in a sow. Jpn. J. Vet. Sci. 46, 247-250.

van den Ingh, T. S. and Rothuizen, J. (1984): Ganglioneuroma of Vater's papilla and extrahepatic cholestasis in a dog. Vet. Pathol. 21, 254-256. 